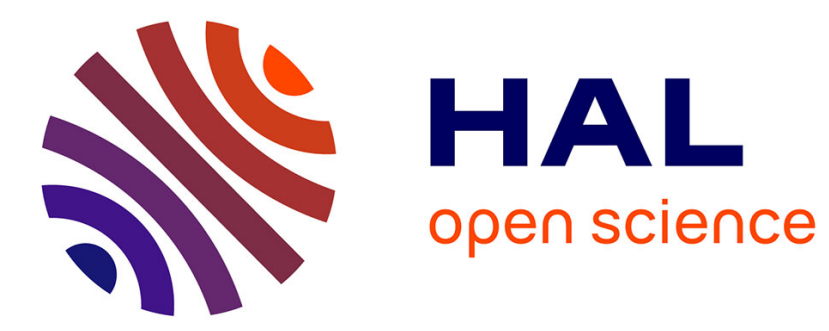

\title{
Generation of interleaved pulses on time-wavelength grid by actively modelocked fibre laser
}

J. Vasseur, M. Hanna, J.M. Dudley, J.-P. Goedgebuer

\section{To cite this version:}

J. Vasseur, M. Hanna, J.M. Dudley, J.-P. Goedgebuer. Generation of interleaved pulses on timewavelength grid by actively modelocked fibre laser. Electronics Letters, 2004, 40 (14), pp.901-902. 10.1049/el:20045248 . hal-00097097

\section{HAL Id: hal-00097097 https://hal.science/hal-00097097}

Submitted on 5 May 2021

HAL is a multi-disciplinary open access archive for the deposit and dissemination of scientific research documents, whether they are published or not. The documents may come from teaching and research institutions in France or abroad, or from public or private research centers.
L'archive ouverte pluridisciplinaire HAL, est destinée au dépôt et à la diffusion de documents scientifiques de niveau recherche, publiés ou non, émanant des établissements d'enseignement et de recherche français ou étrangers, des laboratoires publics ou privés. 


\section{Generation of interleaved pulses on time-wavelength grid by actively modelocked fibre laser}

\section{J. Vasseur, M. Hanna, J.M. Dudley and J.-P. Goedgebuer}

The generation of successive pulses at different wavelengths is demonstrated in an actively modelocked fibre laser. The time and wavelength spacings between emitted pulses are controlled by inser-tion of a phase modulator and a fibre MachZehnder, respectively. Three-wavelength operation at an aggregate rate of 9.4 $\mathrm{GHz}$ is reported.

Introduction: Modelocked lasers emitting picosecond pulses around the $1550 \mathrm{~nm}$ region are potential signal sources for high bit rate optical communication systems. To reduce the cost and increase the capacity of future systems, recent studies have focused on the generation of simultaneous [1-5] or alternate [6-8] multiwavelength pulse trains at $\mathrm{GHz}$ repetition rates. These sources are expected to find wide application in the implementation of 2D wavelength-time optical code division multiple access (OCDMA) [9] and photonic analogue-to-digital conversion [10].

Recently, we proposed a technique to generate successive pulses at different wavelengths using an actively modelocked fibre laser in which an unbalanced Mach-Zehnder interferometer (UMZI) modulator was inserted [11]. However, the times and wavelengths at which the emission of pulses occurred were not controlled. In this Letter, we demonstrate the emission of time-wavelength interleaved pulses on a predetermined grid. Time and wavelength spacings between the pulses are controlled by the insertion of a phase modulator (PM) and a fibre Mach-Zehnder (FMZ), respectively. We demonstrate wavelength locking and time-wavelength locking at multi-GHz repetition rates.

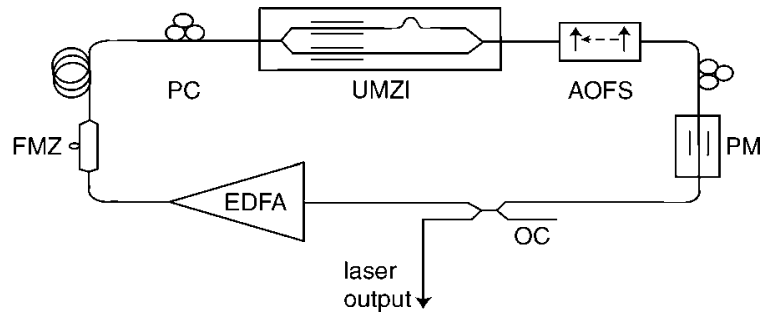

Fig. 1 Experimental setup

PC: polarisation controller; UMZI: unbalanced Mach-Zehnder interferometer; AOFS: acousto-optic frequency shifter; FMZ: fibre Mach-Zehnder; OC: output coupler; PM: phase modulator

Principle: Fig. 1 shows the experimental setup. The UMZI is an integrated annealed proton exchanged $\mathrm{LiNbO}_{3} 10 \mathrm{Gbit} / \mathrm{s}$ modulator that includes a fixed optical path difference of $40 \mu \mathrm{m}$ between its two arms. When no modulating signal is applied onto the UMZI, it behaves as a spectral filter, with a free spectral range of $60 \mathrm{~nm}$. When a radio-frequency signal is applied onto its arms, the frequency transfer function of this component shifts accordingly and acts as a tunable filter. For a fixed wavelength, it plays the role of intensity modulator, achieving modelocking operation of the laser. Because of the frequency selectivity, each wavelength sees a different temporal transfer function, leading to the generation of successive pulses at different wavelengths. An FMZ is inserted in the cavity as a periodic filter and fixes the wavelength spacing to an integer multiple of $\Delta \lambda_{F M Z}=5.8 \mathrm{~nm}$ between the possible emitted wavelengths. Temperature control of this device yields absolute frequency tuning capability. An acousto-optic frequency shifter is introduced in the loop to prevent gain saturation by a single wavelength and to allow multiwavelength laser emission at room temperature [12]. An additional PM is inserted in the cavity to control the time locations of the emitted pulses. By driving the PM at a harmonic of the modulation frequency of the UMZI, pulse emission is locked on a temporal grid. As a consequence, we anchor the laser output on a time-wavelength map. The pulses are amplified in an EDFA and polarisation controllers are used to vary the polarisation orientation. A fused fibre coupler is used to tap the output signal from the laser.
Given that the delay introduced by the UMZI is of the form $\tau(t)=\tau_{0}+\Delta \tau \sin (\Omega t)$, the maximum of the UMZI transfer function, $\omega_{\max }$, is given against time by [11]:

$$
\omega_{\max } \simeq \omega_{0}\left(1-\frac{\Delta \tau}{\tau_{0}} \sin (\Omega t)\right)
$$

where the reference angular frequency, $\omega_{0}$, is chosen to be a maximum of transmission for the filter at $t=0: \omega_{0}=4 k \pi / \tau_{0}$, with $k$ an integer. This condition, along with these time and frequency locking conditions, impose three constraints on the emitted pulses in the time-wavelength domain.

Results: In a first experiment, the PM was not inserted in the ring laser. The laser was driven at $3.8 \mathrm{GHz}$. Fig. $2 a$ shows the time trace and spectrum of the laser output. Three pulse trains at three different wavelengths $\left(\lambda_{1}=1545.3 \mathrm{~nm}, \lambda_{2}=1556.9 \mathrm{~nm}\right.$ and $\left.\lambda_{3}=1562.7 \mathrm{~nm}\right)$ are observed, using an optical spectrum analyser with $0.07 \mathrm{~nm}$ resolution and a sampling oscilloscope with a $30 \mathrm{GHz}$ photodiode. The wavelength of each pulse is identified using a $1.2 \mathrm{~nm}$ filter at the laser output. The wavelengths are separated by $2 \Delta \lambda_{F M Z}$ and $\Delta \lambda_{F M Z}$. The pulsewidths are recorded to be 22,23 and $38 \mathrm{ps}$, respectively. The time-bandwidth product (TBP) of each pulse is $1.92,0.86$ and 0.71 . The chirp is due to the variation of the centre wavelength of the filter with time. Fig. $2 b$ shows the theoretical evolution of the maximum of the transfer function of the UMZI against time (with $\tau_{0}=1.33 \times 10^{-3} \mathrm{~s}, \quad \omega_{0}=1.216 \times 10^{15} \mathrm{rad} / \mathrm{s}, \quad \Omega=2.38 \times 10^{10} \mathrm{rad} / \mathrm{s}$ and $\Delta \tau=1.2 \times 10^{-15} \mathrm{~s}$ as experimental parameters) and the corresponding experimental data points. The unoccupied grid locations arise from residual filtering in the cavity, which can be eliminated by improved cavity design to yield tailored operation at any wavelength on the grid.
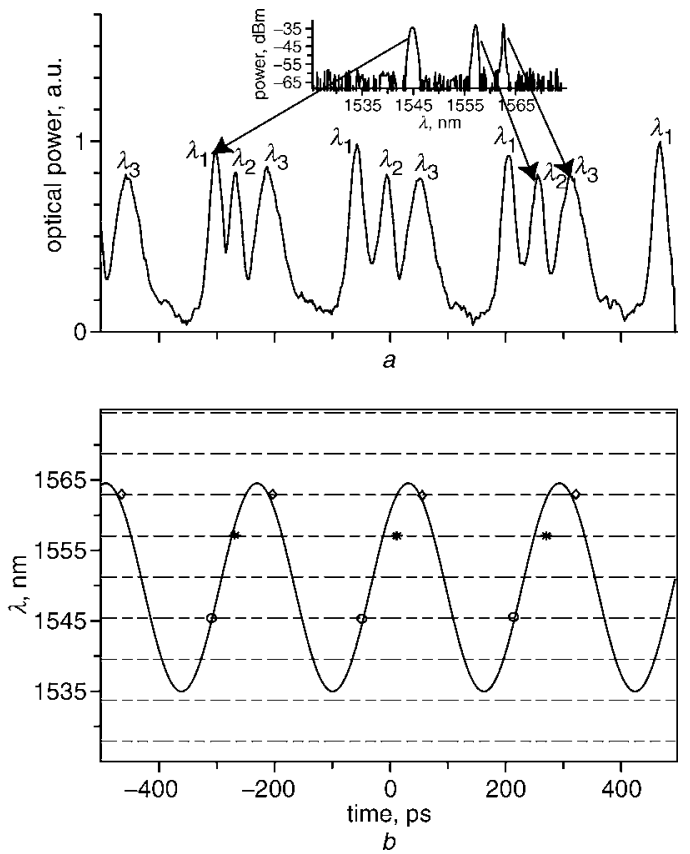

Fig. 2 Time trace and spectrum of laser output and corresponding spectrogram, with theoretical evolution of maximum of UMZI transfer function against time (solid line) and experimental data (points)

$a$ Time trace and spectrum (inset)

$b$ Corresponding spectrogram

It is clear from inspection of Fig. 2 that fluctuations in the temporal spacing between adjacent wavelengths occur. To overcome this problem, we added the PM in the laser cavity. The PM is synchronously driven at an integer multiple of the UMZI modulation frequency to anchor the pulses on a temporal grid. Fig. 3 shows the experimental results when the modulation frequency of the PM $\left(\mathrm{f}_{P M}=9.4 \mathrm{GHz}\right)$ is seven times the modulation frequency of the UMZI $\left(\mathrm{f}_{U M Z I}=1.34 \mathrm{GHz}\right)$. Three pulse trains at three different wavelengths are obtained $\left(\lambda_{1}=1536.9 \mathrm{~nm}\right.$, $\lambda_{2}=1542.7 \mathrm{~nm}$ and $\lambda_{3}=1560.1 \mathrm{~nm}$ ). The pulses at $\lambda_{3}$ and $\lambda_{1}$ are separated by $4 \Delta \lambda_{F M Z}$ in the frequency domain and by $2 / f_{P M}$ in the 
time domain, whereas those at $\lambda_{1}$ and $\lambda_{2}$ are separated by $\Delta \lambda_{F M Z}$ and $1 / f_{P M}$. The pulsewidths are 39,44 and $48 \mathrm{ps}$, yielding a TBP of $0.48,1.1$ and 2.23 , respectively. The emitted pulses are in agreement with the imposed time-frequency grid and the constraint given by (1).
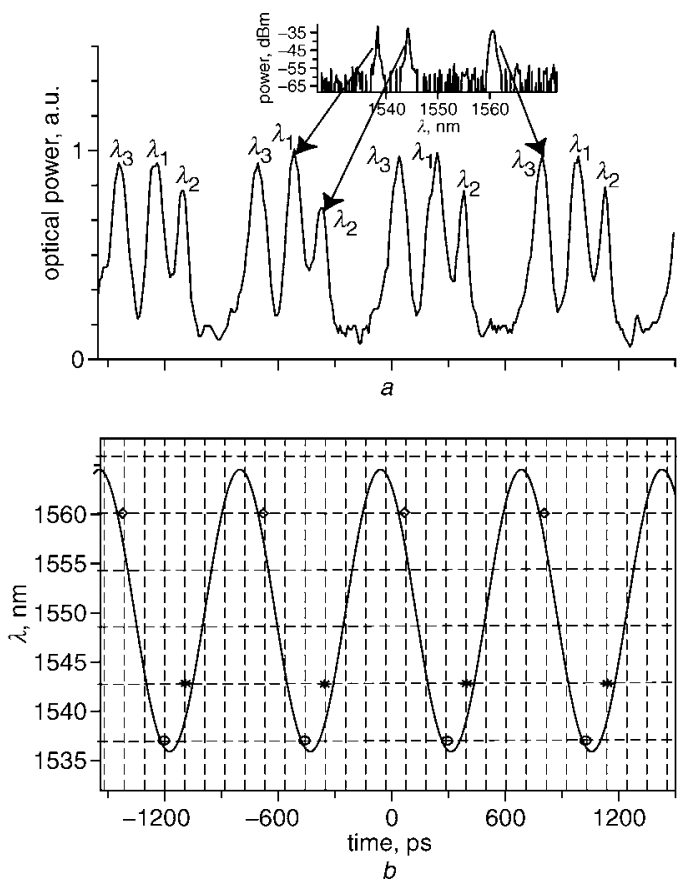

Fig. 3 Time trace and spectrum of laser output and corresponding spectrogram in presence of additional phase modulator, with theoretical evolution of maximum of UMZI transfer function against time (solid line) and experimental data (points)

$a$ Time trace and spectrum (inset)

$b$ Corresponding spectrogram

Conclusion: A new approach to generate time- and wavelengthinterleaved picosecond pulse trains has been experimentally demonstrated by use of an UMZI in an actively modelocked fibre laser. By inserting a periodic filter and a phase modulator in the cavity, a timewavelength mapping is imposed on the laser output. We therefore control the wavelength and time spacings of the emitted pulses. We anticipate that this novel technique will find application for creating codes associating one time slot with one wavelength. This would make the implementation of dynamic 2D-OCDMA feasible.
J. Vasseur and M. Hanna (GTL-CNRS Telecom, UMR CNRS 6174, 2-3 rue Marconi, 57070 Metz, France)

E-mail: jvasseur@georgiatech-metz.fr

J.M. Dudley and J.-P. Goedgebuer (Laboratoire FEMTO-ST, UMR CNRS 6174, Université de Franche-Comté, Route de Gray, 25030 Besançon Cedex, France)

\section{References}

1 Okamura, H., and Iwatsuki, K.: 'Simultaneous oscillation of wavelengthtunable, singlemode lasers using an Er-doped fibre amplifier', Electron. Lett., 1992, 28, pp. 461-463

2 Papakyriakopoulos, T., Stavdas, A., Protonotarios, E.N., and Avramopoulos, H.: ' $10 \times 10 \mathrm{GHz}$ simultaneously modelocked multiwavelength fibre ring laser', Electron. Lett., 1999, 35, pp. 717-718

$3 \mathrm{Li}$, S., and Chan, K.T.: 'Actively mode-locked erbium fiber ring laser using a Fabry-Perot semiconductor modulator as mode locker and tunable filter', Appl. Phys. Lett., 1999, 74, pp. 2737-2739

4 Park, E.D., Croeze, T.J., Delfyett, P.J., Braun, A., and Abeles, J.: 'Multiwavelength mode-locked InGaAsP laser operating at $12 \mathrm{ch} \times 2 \mathrm{GHz}$ and $16 \mathrm{ch} \times 10 \mathrm{GHz}$, IEEE Photonics Technol. Lett., 2002, 14, pp. 837-839

5 Maran, J.-N., LaRochelle, S., and Besnard, P.: 'Erbium-doped fiber laser simultaneously mode locked on more than 24 wavelengths at room temperature', Opt. Lett., 2003, 28, pp. 2082-2084

6 Olsson, A., and Tang, C.L.: 'Time-wavelength multiplexing of modelocked external-cavity semiconductor lasers', IEEE J. Quantum Electron., 1982, QE-18, pp. 1982-1983

7 Town, G.E., Chen, L., and Smith, P.W.E.: 'Dual wavelength modelocked fiber laser', IEEE Photonics Technol. Lett., 2000, 12, pp. 1459-1461

8 Lee, K.-L., Shu, C., and Liu, H.-F.: 'Subharmonic pulse-gating in selfseeded laser diodes for time- and wavelength-interleaved picosecond pulse generation', IEEE J. Quantum Electron., 2004, 40, pp. 205-213

9 Salehi, J.A.: 'Code-division multi-access techniques in optical fiber network-Part I: Fundamental principles', IEEE Trans. Commun., 1989, 37, pp. 824-833

10 Yariv, A., and Koumans, R.G.M.P.: 'Time interleaved optical sampling for ultra-high speed A/D conversion', Electron. Lett., 1998, 34, pp. 2012-2013

11 Vasseur, J., Hanna, M., Dudley, J., and Goedgebuer, J.-P.: 'Alternate multiwavelength modelocked fiber laser', IEEE Photonics Technol. Lett. (accepted for publication)

12 Sabert, H., and Brinkmeyer, E.: 'Pulse generation in fiber lasers with frequency shifted feedback', IEEE J. Lightwave Technol., 1994, 12, pp. $1360-1368$ 